\title{
Фольклористика
}

\author{
УДК $81-139$
}

\section{Р.Д. Урунова}

\section{ЛИНГВИСТИЧЕСКОЕ ПРОЦЕДУРНОЕ ОБЕСПЕЧЕНИЕ ИССЛЕДОВАНИЙ СЮЖЕТА РУССКОЙ ВОЛШЕБНОЙ СКАЗКИ}

Статья посвящена одному из способов исследования сюжета сказки, который был разработан в результате последовательного комплексного осмысления идей и понятий в русской и французской школах сюжетосложения. В статье дается аналитическое представление понятий актанта и актантной модели, а также освещаются основные этапы процедуры их выявления в тексте. Особое внимание уделяется анализу вербального выражения функциональных и качественных характеристик персонажей сказки. Функциональные характеристики позволяют определить актантную позицию героя в модели сюжета, а качественные помогают выявить его духовные черты. В статье методика Греймаса используется с целью корректного выявления структуры сюжета русской народной сказки «Царь-девица». Для иллюстрации исследовательской процедуры приводится фрагмент актантного анализа сказки, в котором представлена процедура исследования параллельного корпуса высказываний, содержащих все характеристики и функциональные сообщения одного из персонажей сказки. В результате семантического анализа вербальных качественных и функциональных характеристик определяется актантная позиция персонажа, которая помогает воссоздать актантную модель, являющуюся конструктивной основой сюжета сказки.

Ключевые слова: сюжет, схема персонажей, корпус высказываний, актантная модель, качественные характеристики, функциональные характеристики.

DOI: $10.35634 / 2412-9534-2021-31-6-1343-1350$

Сюжет сказки - категория, в первую очередь относящаяся к сфере литературоведения, и основополагающим для ее исследования, на наш взгляд, обязательно должны быть труды известного русского ученого Владимира Яковлевича Проппа [6; 7]. В своей главной работе «Морфология сказки» Пропп развил идеи о «формальном» устройстве структуры сюжета русской волшебной сказки [6]. Фактически он трансформировал организацию сказочного мира в структурную модель, которая в той или иной конфигурации лежит в основании любого сказочного сюжета.

Ученый заметил, что несмотря на разнообразие действующих лиц волшебной сказки и окружающего их мира, качество и количество действий (функций) персонажей ограничено: «Постоянными, устойчивыми элементами сказки служат функции действующих лиц, независимо от того, кем и как они выполняются. Они образуют основные составные части сказки» [6, с. 31]. Пропп выяснил, что в русской волшебной сказке используется 31 функция, среди них такие, как:

- отлучение персонажа из дома;

- запрет герою на действие;

- нарушение запрета;

- получение вредителем информации о жертве;

- обман жертвы вредителем;

- невольное пособничество жертвы вредителю и т. д.

Эти функции в разных наборах повторяются из одной сказки в другую. Пропп обратил внимание на то, что «разнообразные сказочные персонажи в различных сказках действуют одинаково». И это наблюдение позволило ему среди всех функций выявить основные, которые фактически являются сущностными, а потому их можно считать базовыми для организации сюжета любой волшебной сказки. Базовые функции для разных персонажей являются основанием для характеристики, и поэтому разнообразные герои сказок являются однотипными функциональными персонажами. Исследовав их, Пропп получил семиперсонажную схему, которая лежит в основе любого сказочного сюжета:

1) вредитель,

2) даритель,

3) помощник, 
4) искомый персонаж и его отец,

5) отправитель,

6) герой,

7) ложный герой.

Характеристики действующих лиц в разных сказках разнообразные, также меняются способы осуществления базовых функций, но сами функции остаются неизменными. Пропп, изучив русские волшебные сказки, пришел к выводам:

1. Постоянными элементами сказок являются функции действующих лиц.

2. Число этих функций ограничено.

3. Последовательность функций в сказках всегда одинаковая, поэтому все волшебные сказки однотипны по строению.

Труд В.Я. Проппа, не имевший особого успеха на родине, оказал мощнейшее влияние на французскую семиотическую школу, которая в сфере исследований сюжетосложения, безусловно, занимает одно из ведущих мест в мировой науке.

Знакомство европейских ученых с «Морфологией сказки» положило начало дальнейшему осмыслению пропповской сюжетной модели. Одним из первых откликов на эту работу стала статьярецензия французского этнолога К. Леви-Стросса, который считал концепцию В.Я. Проппа «великим открытием, предвосхитившим на четверть века попытки, предпринятые в этом же направлении другими» [5, с. 33]. Он видел возможность «генерализации пропповской модели, чтобы сделать ее применимой к любому фольклорно-мифологическому повествованию» [3, с. 115]. И хотя сам Пропп не был согласен с таким широким подходом, интерпретация Леви-Стросса задала направление последующим разработкам морфологии сказки.

После работ Леви-Стросса следующим шагом в осмыслении и обработке пропповской модели стала книга французского семиотика А. -Ж. Греймаса «Структурная семантика» [1]. Греймас сосредоточился на радикальной формализации и универсализации семиперсонажной схемы Проппа. Написав ряд трудов, Греймас разработал лингвистическую методику, которая позволяла математически точно выявлять персонажную схему в тексте сказки, и поэтому в конце концов стала процедурным обеспечением концепции Проппа. Лингвистическая методика Греймаса в дальнейшем помогла вывести пропповскую модель в область общего сюжетосложения за рамки фольклорно-мифологического материала, как этого хотел Леви-Стросс.

А.-Ж. Греймас на основании пропповской семиперсонажной схемы сформулировал новое в филологии понятие обобщенной актантной модели [2, с. 127]. Обобщенной модель является потому, что позволяет исследователю выйти за границы сказочных сюжетов. Актантная модель Греймаса в настоящее время признана всеми классической, поскольку она позволяет описать если не все, то значительную часть любых повествовательных текстов, если в их основе лежит отношение субъект $\rightarrow$ объект.

В настоящей статье поставлена цель - применить актантную модель Греймаса для выявления структуры сюжета русской народной сказки «Царь-девица». За основу исследования берутся положения и категории, изложенные в «Морфологии сказки» Владимира Проппа, которые обеспечиваются применением лингвистической методики Греймаса. Такая организация исследования, на наш взгляд, должна была обеспечить объективность и корректность его результатов.

Основным понятием для исследования структуры сюжета с точки зрения пропповской морфологии является функциональный для сюжета персонаж, он же с точки зрения Греймаса - актант. И хотя непосредственная связь между этими понятиями очевидна, необходимо уточнить их общие и различающиеся качества. Термин «актант» в парадигму сюжетосложения ввел А. -Ж. Греймас, позаимствовав его из структурного синтаксиса французского лингвиста Люсьена Теньера [8, с. 117-130], таким образом ученый соединил две идеи: организующего сюжет сказки пропповского «персонажа» и актанта, являющегося постоянным конструктивным элементом синтаксических моделей. Семиотик не просто использовал отдельный термин Теньера, он применил главные принципы парадигмы актантного синтаксиса в процедуре лингвистического обеспечения исследований сюжета и вывел сюжетную модель на уровень «нарративного синтаксиса». Греймас вводит термин «актант», постоянно сопоставляя его с базовыми понятиями концепции Проппа. Он описывает, каким образом пропповская схема персонажей трансформируется в актантную модель: «Актанты, которые суть не что иное, как классы актеров, поддаются определению, лишь исходя из корпуса всех сказок без исключения: распределение актеров создает отдельную сказку, а структура актантов - жанр» [2, с. 121]. Для Греймаса особенно важ- 
но, что актантная модель по отношению к персонажной сказочной схеме является конструктивным инвариантом: «Актанты, таким образом, обладают металингвистическим статусом по отношению к актерам ${ }^{1}$; кроме того, они требуют исчерпывающего функционального анализа, иначе говоря, установления кругов действий [2, с. 121].

Для чистоты исследования сюжета Греймас предлагает выявлять актанты из текста и давать их характеристику путем двухуровневого лингвистического анализа. Таким образом, он стремится придать персонажной схеме Проппа конкретное языковое воплощение. Схема персонажей в вербальной форме является фактическим выражением актантной модели. Процедура работы с языковым материалом текста позволит исследователю точно определить актантный статус каждого героя, а набор всех актантов - сюжетную схему текста.

Лингвистический анализ должен выявить характеристику сказочного персонажа в двух аспектах:

- качества, присущие герою сказки;

- функция, которую герой выполняет в организации сюжета.

Для определения качественных характеристик персонажа необходимо осуществить отбор единиц текста, «которые можно обнаружить в форме прозвищ, устойчивых эпитетов, ... атрибутов или же в развернутых высказываниях, содержащих суждениях» [2, с. 118]. По установленному корпусу высказываний исследователь получает возможность определить «духовные качества» героя [2, с. 118]. Качественные характеристики не являются значимыми для актантного статуса персонажа. Они важны, скоpeе, для колорита и стиля повествования, а не для конфигурации сюжета, но они придают актанту конкретное выражение в тексте сказки, и без них выявление актанта и сюжетной модели было бы невозможным. Для выявления качественных характеристик героя необходимы следующие единицы текста:

1) слова-прозвища, то есть слова с переносным значением, которые называют героя (их уместно считать номинативами $[9$, с. 23]);

2) определения всех видов, примененные к герою в контексте (их уместно назвать атрибутивами $[9$, c. 23]);

3) суждения героя, выраженные конструкциями прямой и косвенной речи.

Так в сказке «Царь-девица» персонаж «мачеха» выражен следующим образом: 1) Взял за себя молодую жену, и сделалась она в доме полной хозяйкою, Василью-иаревичу злою мачехой.

- слова: жена, хозяйка, мачеха - номинативы;

- слова: молодая, полная, злая - атрибутивы.

2) Говорит ему иарица: "Вот тебе медная булавка, воткни ее царевичу в ворот кафтана; тогда он заснет крепким сном, и кто б ни пришел, кто бы ни приехал - ни за что его не разбудит!»

- слова: медная булавка, воткни ее - характеризуют мачеху как колдунью.

Данное вербальное выражение качественных характеристик, не требует дополнительных операций для толкования, достаточно использовать толковый словарь. Все слова являются выражением духовного облика персонажа: мачеха - молодая, властная, злая, коварная. Такими качествами в сказке могут обладать вредитель и ложный герой, следовательно, для точности необходим анализ «функциональных сообщений».

Для определения функциональных характеристик, которые позволяют выявить актантный статус героя, устанавливается параллельный корпус фрагментов текста, содержащий «функциональные сообщения», которые называются функтивами [9, с. 23]. К ним относятся фрагменты, в которых сообщается о действиях, совершаемых персонажем, поэтому чаще всего функтивами в тексте являются глаголы. Греймас, вслед за Проппом, считает, что именно «функции создают актантов», поэтому у функтивов особое предназначение в сказке [2, с. 127]. Для сюжета сказки функтивы являются конструктивными единицами. Так в сказке «Царь-девица» персонаж «мачеха» имеет следующие функциональные характеристики:

сделалась она в доме полной хозяйкою; иарь заболел и помер, а иарииа связалась с дядькою; дядька тому и рад, побежсал с мачехой тешиться; Дядька побежал с докладом к мачехе; Говорит ему иярица: «Вот тебе медная булавка, воткни ее царевичу в ворот кафтана» и т. д.

После того, как фактический материал собран, необходимо осуществить собственно анализ: «Исходя из набора функциональных сообщений, исследователь - с помощью последовательных про-

\footnotetext{
${ }^{1}$ Греймас в данном случае использует термин Теньера «актер» вместо пропповского термина «персонаж» как «прозрачный» по семантике и близкий к актантной интерпретации сюжета.
} 
цедур редукции и гомологизации - получает возможность определить явление, которое можно назвать сферой деятельности» персонажа сказки [2, с. 118].

Редукция помогает осуществить отбор важных для актанта единиц, путем упрощения, сведения его сложной контекстной семантики к более доступной, понимаемой в аспекте актантной модели. Так, например, во фрагменте связалась с дядькою - функтив связалась содержит дополнительное значение негативной оценки того действия, которое является основным для глагола. Эта негативная коннотация важна для актантной характеристики персонажа, больше, чем основное значение функтива, поскольку выполняет в данном случае роль фильтра: актанты - помощник, даритель, искомый персонаж - не могут совершать действия, вызывающие негативную оценку.

Процедура гомологизации позволяет идентифицировать определенную актантную функцию в семантике разных глаголов.

Таким образом, все выписанные из сказки фрагменты с функциональными характеристиками идентифицируются ${ }^{2}$ путем сравнения, и на их основе определяется, какую актантную позицию в модели занимает тот или иной персонаж. После этого из полученных актантов выстраивается собственно актантная модель, представление которой «во временной последовательности» отображает сказочный сюжет [2, с. 121].

Применение понятий и процедур, предложенных Греймасом, помогло выявить актантную модель сказки «Царь-девица» в следующей последовательности:

- На первом этапе процедуры был установлен «корпус высказываний», которые являются базовыми для идентификации «сферы деятельности актанта» и его «духовного облика».

- На следующем этапе при помощи толкового словаря или путем применения компонентного анализа было определено качество каждого «высказывания» по степени актуализации в нем возможных актантных ролей.

- Затем были осуществлены редукция и гомологизация функциональных характеристик персонажа, в результате оказались отобраны те функтивы, которые являются значимыми для построения актантной модели.

- На заключительном этапе была составлена актантная модель сказки.

Поскольку полный анализ текста сказки является слишком объемным для статьи, для примера приведем образец анализа только одного персонажа - Ивашки белой рубашки, сорочинской шапки:

1. Фрагменты с номинативами:

Как же мне не знать тебя, коли я у твоего батюшки тридияать лет в пастухах служил!;

Зовут меня Ивашка белая рубашка, сорочинская шапка;

Допреже того был я первылм воеводою, да отеи твой разгневался и за провинок сослал меня $\underline{6}$ $\underline{\text { nacmyxu } \gg . ~}$

2. Фрагменты с атрибутивами:

Зовут меня Ивашка белая рубашка, сорочинская шапка;

Допреже того был я первым воеводою, да отеи твой разгневался и за провинок сослал меня в nacmyxu».

3. Фрагменты с функтивами:

Говорит ему Ивашка: "Не посмотря твоей силь, нельзя тебе и коня указать. Вот стоит ракитовый куст, попробуй - выдерни его с корнем». Василий-царевич ухватился за куст и выдернул его с корнем - под тем кустом лежит меч-кладенеи, боевая палица и вся богатырская сбруя: узда в три пуда, седло в двадиать пять пудов, боевая палииа в полтораста пудов.

«Ну, иаревич, дожидай меня здесь, - говорит Ивашка белая рубашка, сорочинская шапка, поутру пригоню я стадо кониное, впереди в воду и_попльвут далеко-далеко, а как солнышко с полудня своротит да свадит жар, станет тот жеребец выгонять кобылицу в зеленые луга. В те поры смотри не зевай: только ступит жеребец на берег, тотчас и бей его промежду ушей своей палицей».

В результате обобщения приведенного «корпуса высказываний» были выявлены следующие характеристики Ивашки белой рубашки, сорочинской шапки:

1. Прозвище героя - «белая рубашка, сорочинская шапка», так как он, очевидно, всегда ходил в белой рубашке и в сорочинской шапке.

2. Он был главным воеводою у отца Василия-царевича.

\footnotetext{
2 По Греймасу, подвергаются гомологизации.
} 
3. Отец Василия-царевича разгневался и за какой-то, очевидно, лихой поступок Ивашки «сослал» его в пастухи.

4. Ивашке много лет, так как он прослужил в пастухах тридцать лет, а до этого был воеводою.

5. Ивашка знает Василия-царевича с его раннего детства.

6. Ивашка испытывает Василия-царевича, уясняет, насколько он сильный, так как без силы нельзя получить коня.

7. Ивашка передал Василию-царевичу меч-кладенец, боевую палицу и всю богатырскую сбрую: узду в три пуда, седло в двадцать пять пудов.

8. Ивашка научил Василия-царевича, как получить коня.

Анализ качественных и функциональных характеристик героя, дополненных актантными характеристиками Василия-царевича, позволяет сделать вывод о том, что в сказке Ивашка белая рубашка, сорочинская шапка выполняет функцию дарителя. Конечно, этот герой помогает Василию-царевичу приобрести коня и необходимые ему предметы, а не просто дарит, но в этом проявляется отношение к героям в русских сказках. Амуниция не могла быть просто подарена герою, он должен был ее добыть сам. Учитывая то, что функция Ивашки в сказке ограничивается только тем, что Василий-царевич получает боевое оснащение, делаем вывод, что Ивашка - даритель.

Анализ выявленных из текста «функциональных сообщений» и «сообщений характеристик» показывает, что структурная модель сказки «Царь-девица» является полной семиперсонажной и состоит из следующих актантов:

1. Герой - Василий-царевич;

2. Искомый персонаж - Царь-девица;

3. Вредитель - мачеха и дядька;

4. Даритель - Ивашка белая рубашка, сорочинская шапка;

5. Помощник - лев, змей, ворон и конь;

6. Отправитель - лев, змей, ворон;

7. Ложный герой - Иван-богатырь.

По А. -Ж. Греймасу, чтобы модель была воссоздана точно, исследователю необходимо учесть трансформации актантных единиц в сюжете сказки, так как они могут: расщепляться, соединяться или вообще «отсутствовать» в сюжете [2, с. 131-132]. В сказке «Царь-девица» «аналитическое разделение» [2, с. 131] происходит с актантом «помощник», расщепленным на четыре персонажа (лев, змей, ворон и конь), и с актантом «вредитель», который расщепляется на двух персонажей - мачеху и дядьку. Также в сказке встречается и совмещение сюжетных функций, которое Греймас назвал «синкретизмом актантов» [2, с. 131]. В данной сказке лев, змей и ворон совмещают функции сразу двух актантов - отправителя и помощника. Прием «отсутствующий актант» [2, с. 132] в сказке не встречается, поэтому актантная модель представлена всеми семью позициями.

Таким образом, в сказке «Царь-девица» наблюдаются следующие актантные процессы:

1) Расщепление актантов

«Помощник»

$$
\left\{\begin{array}{l}
\text { лев, змей и ворон } \\
\text { конь } \\
\text { царь-лев, царь-змей, царь-ворон }
\end{array}\right.
$$

«вредитель»

мачеха

дядька

«отправитель»

лев, змей, ворон

Царь-девица 
2) Синкретизм актантов:

Лев, змей и ворон

$$
\begin{aligned}
& \left\{\begin{array}{l}
\text { «отправитель» } \\
\text { «помощник» }
\end{array}\right. \\
& \left\{\begin{array}{l}
\text { «искомый персонаж» } \\
\text { «отправитель» }
\end{array}\right.
\end{aligned}
$$

Таким образом, в сказке «Царь-девица» пятнадцать персонажей выполняют семь сюжетообразующих функций. Преобладание количества действующих лиц над количеством актантных позиций в структурной модели и полный комплект последних позволяет считать объем сказки большим, тогда как модели, в которых количество персонажей меньше семи и, следовательно, в актантной модели представлены не все позиции, имеют маленький объем.

Анализ текста по методике А.-Ж. Греймаса показал, что в сказке «Царь-девица» Василийцаревич является центральным персонажем. Поступки и поведение других персонажей связаны с его действиями, и их функциональная характеристика всегда определяется относительно его характера и поведения. Это позволяет сделать вывод о том, что Василий-царевич - конструктивный центр актантной модели сказки. Учитывая это, можно представить актантную модель сказки в следующей схеме:

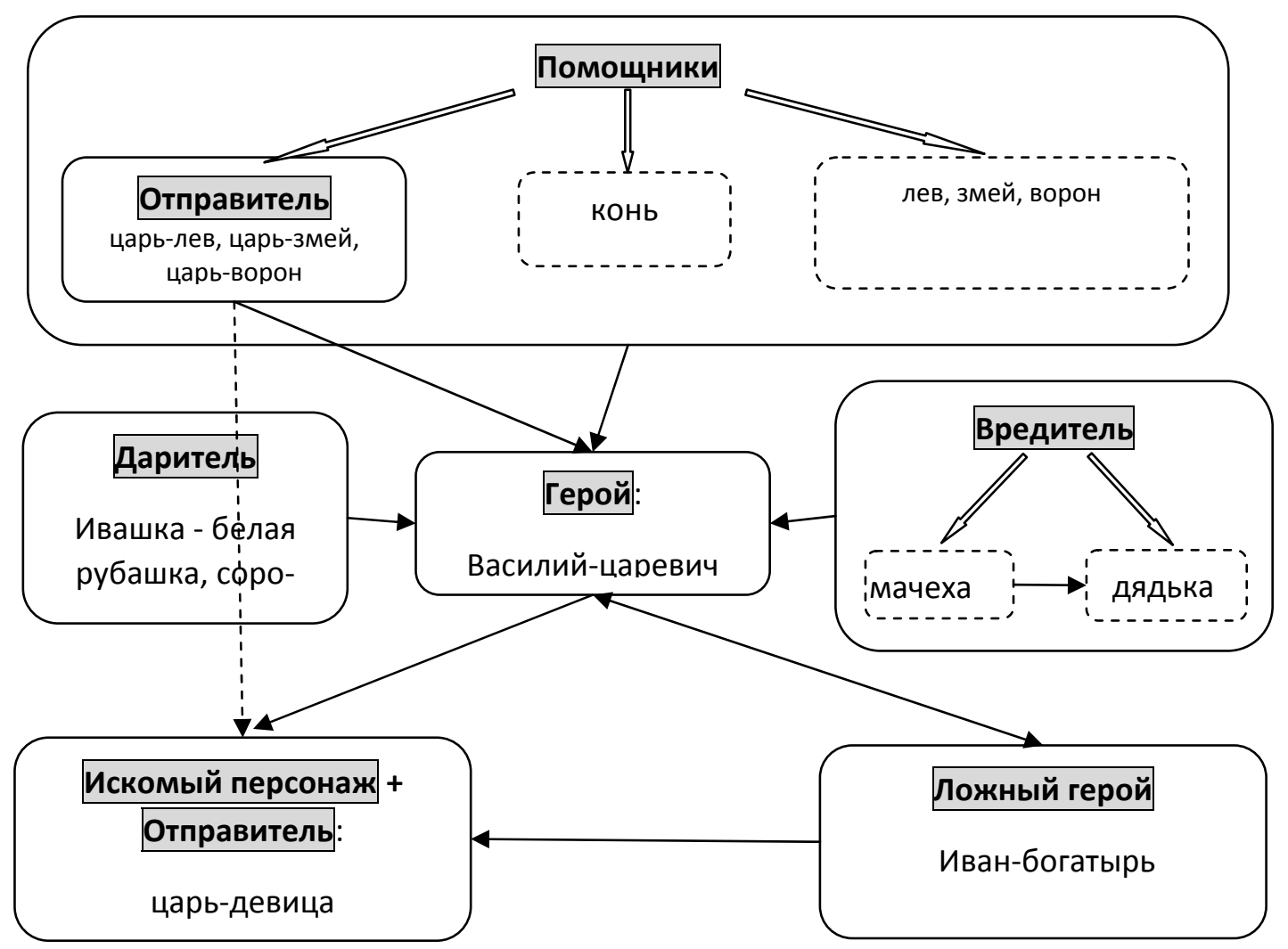

В заключении необходимо отметить, что несмотря на типизированный характер сюжетов, очарование волшебных сказок разных народов заключается как раз в том, чем они отличаются, поскольку часто разнообразие персонажей, их внешности, поступков, выраженное номинативами и атрибутивами, отражают национальный характер, «уклад жизни народа, особенности той среды, в которой они бытуют, изменения быта, местные природные условия, трудовые процессы» [10, с. 162]. Таким образом, не- 
смотря на то, что номинативы и атрибутивы не являются конструктивными единицами актантных моделей, как раз они и являются отражением народной культуры [6, с. 96], поэтому оказываются особенно ценными для жанра сказки.

\title{
СПИСОК ЛИТЕРАТУРЫ
}

1. Греймас А.-Ж. Структурная семантика: Поиск метода. М.: Академический Проект, 2004.368 с.

2. Греймас А.-Ж. Размышление об актантных моделях // Вестник Московского университета. Серия 9. Филология. 1996. № 1. С. 118-136.

3. Косиков Г.К. От Проппа к Греймасу // Вестник Московского университета. Серия 9. Филология. 1996. № 1. С. 114-118.

4. Леви-Стросс К. Структура и форма. Размышление об одной работе Владимира Проппа // Семиотика. М.: Радуга, 1983. С. 400-428.

5. Леви-Стросс К. Структура и форма. Размышление об одной работе Владимира Проппа. Послесловие // Зарубежные исследования по семиотике фольклора: сб. ст. М.: Наука, 1985. С. 9-34.

6. Пропп В.Я. Морфология «волшебной» сказки. М.: Лабиринт, 1998. 512 с.

7. Пропп В.Я. Структурное и историческое изучение волшебной сказки // Семиотика. М.: Радуга, 1983. С. $566-584$.

8. Теньер Л. Основы структурного синтаксиса. М.: «Прогресс», 1988. 656 с.

9. Урунова Р.Д. Концепция В. Проппа и актантный анализ текстов // Ученые записки Ульяновского государственного университета. Сер. Лингвистика. Ульяновск: Изд-во УлГУ, 2019. Вып. 1(23). С. $22-26$.

10. Сумцов Н. и др. Сказки // Энциклопедический словарь. СПб.: Изд. Ф.А. Брокгауз, И.А. Ефрон, 1900. Т. ХХХ. C. 62-165. URL: http://feb-web.ru/feb/skazki/encyclop/sbe-162-.htm

11. Афанасьев А.Н. «Царь-девица» // Народные русские сказки. М.: Государственное издательство художественной литературы (Гослитиздат), 1957-1958. Т. 2. С. 144-151. URL: http://www.ru-skazki.ru/queen-1.html

Поступила в редакцию 30.01.2021

Урунова Раиса Джавхаровна, доктор филологических наук, доцент кафедры русского языка

ФГАОУ ВО «Казанский (Приволжский) федеральный университет»

420008, Россия, г. Казань, ул. Кремлевская, 25

E-mail: urunova-rd@yandex.ru

\section{R.G. Urunova}

\section{LINGUISTIC PROCEDURAL SUPPORT FOR THE RESEARCH OF THE RUSSIAN FAIRY TALE PLOT}

\author{
DOI: $10.35634 / 2412-9534-2021-31-6-1343-1350$
}

The article is devoted to one of the ways of studying the plot of a fairy tale, which was developed as a result of a consistent comprehensive understanding of ideas and concepts in the Russian and French schools of plot composition. The article provides an analytical representation of the concepts of the actant and the actant model, as well as highlights the main stages of the procedure for identifying them from the text. Special attention is paid to the identification and analysis of the verbal expression of the functional and qualitative characteristics of the characters of a fairy tale. Functional characteristics allow us to determine the actant position of the hero in the plot model, and qualitative characteristics help to identify his spiritual traits. In the article, Greimas's methodology is used to correctly identify the plot structure of the Russian folk tale "The Tsar Maiden". To illustrate the research procedure, a fragment of the actant analysis of the fairy tale is given, which presents the procedure of studying a parallel corpus of statements, containing all characteristics and functional messages of one of the characters of the fairy tale. As a result of the semantic analysis of verbal qualitative and functional characteristics, the actant position of the character is determined, which helps to reconstruct the actant model, which is the constructive basis of the tale's plot.

Keywords: plot, character scheme; body of statements, actant model; qualitative characteristics, functional characteristics.

\section{REFERENCES}

1. Grejmas A.-Zh. Strukturnaya semantika: Poisk metoda [Structural semantics: the Search method]. M.: Akademicheskij Proekt, 2004. 368 s. (In Russian).

2. Grejmas A.-Zh. Razmyshlenie ob aktantnyh modelyah [Thinking about actant models] // Vestnik Moskovskogo universiteta [Bulletin of the Moscow University]. Seriya 9. Filologiya. 1996. № 1. S. 118-136. (In Russian). 
3. Kosikov G.K. Ot Proppa k Grejmasu [From Propp to Greimas] // Vestnik Moskovskogo universiteta [Bulletin of the Moscow University]. Seriya 9. Filologiya. 1996. No. 1. S. 114-118. (In Russian).

4. Levi-Stross K. Struktura i forma. Razmyshlenie ob odnoj rabote Vladimira Proppa [Structure and form. Reflection on a work by Vladimir Propp] // Semiotika [Semiotics]. M.: Raduga, 1983. S. 400-428. (In Russian).

5. Levi-Stross K. Struktura i forma. Razmyshlenie ob odnoj rabote Vladimira Proppa. Posleslovie [Structure and form. Reflection on a work by Vladimir Propp. Afterword] // Zarubezhnye issledovaniya po semiotike fol'klora [Foreign studies on the semiotics of folklore] / Sbornik statej. M.: Nauka, 1985. S. 9 -34. (In Russian).

6. Propp V.Ya. Morfologiya «volshebnoj» skazki [Morphology of the "magic" fairy tale]. M.: Izd-vo Labirint, 1998.512 s. (In Russian).

7. Propp V.Ya. Strukturnoe i istoricheskoe izuchenie volshebnoj skazki [Structural and historical study of the fairy tale] // Semiotika [Semiotics]. M.: Raduga, 1983. S. 566-584. (In Russian).

8. Ten'er L. Osnovy strukturnogo sintaksisa [Fundamentals of structural syntax]. M.: Progress, 1988. 656 s. (In Russian).

9. Urunova R.D. Koncepciya V. Proppa i aktantnyj analiz tekstov [V. Propp's concept and actant analysis of texts] // Uchenye zapiski Ul'yanovskogo gosudarstvennogo universiteta [Scientific Notes of Ulyanovsk State University]. Ser. Lingvistika. 2019. Ul'yanovsk: Izd-vo UlGU. Vyp. 1 (23). S. 22-26. (In Russian).

10. Sumcov N. i dr. Skazki // Enciklopedicheskij slovar' [Fairy tales // Encyclopedic dictionary]. SPb.: Izd. F.A. Brokgauz, I.A. Efron, 1900. T. XXX. S.62-165. URL: http://feb-web.ru/feb/skazki/encyclop/sbe-162-.htm (In Russian).

11. Afanas'ev A.N. Tsar'-devitsa // Narodnye russkie skazki [The Tsar-maiden / Russian Folk Tales]. M.: Gosudarstvennoe izdatel'stvo khudozhestvennoj literatury (Goslitizdat), 1957-1958. Tom 2. S. 144-151. URL: http://www.ru-skazki.ru/ queen-1.html (In Russian).

Urunova R.D., Doctor of Philology, Associate Professor at Department of Russian language

Kazan (Volga region) Federal University

Kremlevskaya st., 25, Kazan, Russia, 420008

E-mail: urunova-rd@yandex.ru 